\title{
CRITICAL SUCCESS FACTORS OF STRATEGIC ACCOUNTING INFORMATION SYSTEM AND IT'S RELATION WITH STRATEGIC DECISIONS EFFECTIVENESS
}

\author{
Hakeem Hammood Flayyih ${ }^{1}$, Aws Saeed Mirdan², Abderrazek Hassan Elkhaldi ${ }^{3}$ \\ ${ }^{1}$ Candidate student Institut Supérieur de Gestion de Tunis, Tunis. \\ College of Administration and Economics, University of Baghdad, Iraq \\ ${ }^{2}$ College of Physical Education and Sport Science, University of Wasit, Iraq. \\ ${ }^{3}$ Faculty of Economic Sciences and Management of Sousse University of Sousse, Tunis \\ hakeem.hmood@coadec.uobaghdad.edu.iq \\ aws.mrdan@uowasit.edu.iq \\ abderrazek.elkhaldi1@gmail.com
}

\begin{abstract}
This paper attempts to explain the critical success factors of strategic information system (SIS) and it's relation with strategic decisions effectiveness. An analysis demonstrated that SIS advancement began from a mechanical concentration toward a procedure concentrating on complementary association with firms' system and notwithstanding setting business technique and driving hierarchical change and structure. Primarily, the best SIS is coordinated such that better fits the affiliation properties for the culture, structure, style and limits. Finally, strategist's effort to improve the fragmented data they have dependent on their past experience and claim intellectual styles. In this way any choices made would be made reliant on the strategist's qualities, convictions and experience, which at last could confine the decisions that they make. Basically, then qualities fill in as outlines or establishments for deciding, tackling issues and settling clashes.
\end{abstract}

Keywords: strategic information system, strategic decisions effectiveness, competency

\section{JEL Classification: M41}

\section{Introduction}

Strategic Information System (SIS) is the distinguishing proof of a heap of PC based capacities that will help a firm in perceiving its business objectives and achieving its marketable strategies (Bhattacherjee \& Hikmet, 2007). The writing analysis demonstrated that SIS advancement began from a mechanical concentration toward a procedure concentrating on complementary association with firms' system and notwithstanding setting business technique and driving hierarchical change and structure (Bignell \& Fortune, 1984). Amid the previous decade, scientists have proposed numerous models for the SIS achievement. In like manner, as of late, as associations vigorously depend on data frameworks for upper hand and execution improvement, the administrators understood the essentialness of SIS as well (Bignell \& Fortune, 1984).

There are three stages in most of the systems of an organization. The first stage in the system is the data which is the input. The information is the product of the system operations. The data that is entered into the information system for processing is the input. The information system collected and processed the data. () stated that data alone are meaningless and useless until they are addressed and transformed into a useful, structured and meaningful form, which is then called information (Thijeel, Flayyih and Talab, 2018).

Data are the beginning of the system's operation and are facts that are in the form of abstract numbers or symbols. (Romney \& Steinbart, 2009) added that data are facts and figures, which are collected, stored and transformed by information systems and can be expressed as facts. (Hall, 2008). Data can be classified into two main categories: the first category is the financial data that relate to all economic events that occur in the organization and are followed by a financial impact that can be measured and expressed in financial terms and 
non-financial statements. This is related to quantitative data, which can be expressed quantitatively, such as the preparation of workers, the number of hours worked, the number of shares, the number of units sold. The second category is the data that are not quantifiable nor expressed quantitatively because they are difficult to be measured either quantitatively or quantitatively. (Al Jabouri \& Kadhum, 2021) concluded that there is an extent to which training programs are used for employees and consumer tastes.

According to Hall (2008), apart from the simple definition of information that, information is often defined simply as the data being processed which is not enough, Information is determined by its effect on the user, not on its physical form. Information is the data that is organized and processed to give meaning to the user. Users need information to make decisions or to develop decision-making. Generally, as the quality and quantity of information increases, the user can make better decisions (Romney and Steinbart, 2009).

Generally, information provided by SMEs can be categorized into two main types: the first one is the mandatory information which is provided to government agencies or lenders; and the optional information that is provided to the internal parties of the organization. One of its conditions and characteristics is that the information must reduce the uncertainty of the decision-maker and the information should increase the knowledge of the decision-maker. In contrast, if it is not beneficial, it will be added to the knowledge of the decision-maker which may benefit from the future process of delayed decision. Thus, the information must be provided by the system, great values while the information must be essential to any connection between the internal and external parties (Al-taie \& Flayyih, 2020).

There has been considerable interest in recent year in supporting and replacing accounting information with non-financial information in a number of uses such as cost and profit forecasting and corporate valuation. The joint use of financial and non-financial information has different results and the benefits of those use has been documented by researches. To measure non-financial performance accurately and to appropriately evaluate and weigh metrics when multiple accounting and non-financial measurements are used are the two important changes in the use of accounting integration with non-financial information. These challenges have to do with the nature and magnitude of the measurement error. Loft (2009) mentioned that this helps to place appropriate weights on multiple scales.

The data processed and submitted to users must have characteristics that differ from those identified by the FASB in Statement 2 according to the new joint framework of the Financial Accounting Standards Board (IASB) and the International Accounting Standards Board (IASB) (SFAC 2 1982). The basic characteristics according to the common framework and the specific characteristics of accounting information are the appropriateness and honesty in representation (Flayyih et al., 2020).

\section{Management Control Systems (MCS)}

The literature review found several definitions of Management Control Systems (MCS). According to (Henri, 2006), MCS are defined as formalized procedures and systems that use information to maintain or alter patterns in an organizational activity. This definition includes planning systems, reporting systems, and monitoring procedures that are based on information use. Akroyd, \& Maguire, (2011) were used MCS concept (citation and sentences) which was developed by Anthony (1965) as the process by which management ensures that resources are obtained and used effectively and efficiently in the accomplishment of the organization's objectives. However, Bisbe, \& Otley, (2004) have focused on MCS definition by Simons (1995) refered to management control systems as the formal, information-based routines and procedures managers use to maintain or alter patterns in organizational activities. Other researchers (Valeiras,Sanchez \& Conde (2015)used Chenhall (2003) study, which indicated to MCS consist of systematic use of management accounting to achieve some goals and other controls such as personal and clan controls. 
MCS have been categorized in different ways in the literature. Some of these categorizations are formal and informal controls, action and results controls, tight and loose controls, and financial and non-financial controls (see for instance; Kald et al., 2000; Langfield- Smith, 1997; Simons, 1991). Thus, it has been argued that to make MCS more relevant in today's competitive environment there is the need to go beyond financial analysis and to include nonfinancial analysis (Chenhall, 2003; Nyamori, Perera, \& Lawrence, 2001). Simons's (2005) classification of controls into diagnostic and interactive provides a useful reference for understanding the distinction between financial and non-financial MCS. Diagnostic controls tend to be backward and inward-looking and can be associated with financial MCS while interactive controls tend to be forward and outward-looking and can be associated with nonfinancial MCS.

Financial and non-financial MCS are both important when it comes to strategy development (Alkhafaji et al., 2018) May be better combine with the above paragraph. In this review, we found various definitions of business strategy, and most of selected papers have defined business strategy is concerned with how a business achieves competitive advantage and it has been suggested that the MCS should be tailored explicitly to support the strategy of the business to lead to superior performance, for instance Henri, (2006); Acquaah, (2013).

\section{The Relationship between MCS, Business Strategy and Firms Performance}

Introduced(Watts et al., 2012) the new performance measurement and MCS. However, the authors find that the small business performance pyramid and performance wheel imply that numerous models of control can be lowered to one overarching model. This is because it takes into cognizance and incorporate the weakness of the prior models and also provide broadly a model of performance management capable to be adopted so as to meet the demands of any organisation. The implication of this research is the creation of the pyramidmodel of control for small firms without taking into consideration the larger firms.

In (Landfield \& Zechmann, 1997) article review studies relationship between MCS and business performance. The author finds that very few research "empirical" papers were published considering the strategy as an interest in both professional and academic literature in recent times. The contingency studies focused on identifying the characteristics of MCS associated with effectiveness under different strategies. However, the research evidence is fragmentary and sometimes conflicting. These conflicts were believed to be partially a result of the differences in research designs (as occurs in all contingency research), but also arose from the way that control, effectiveness and strategy were operationalised and measured. Future research in this area could aim to develop this consistently (AI-Ani\& FLAYYIH,2018).

\section{Strategic Information System}

Be that as it may, regardless of its potential advantages, the quantity of effective SISs is appeared to be observably low. Subsequently, contemplating SIS achievement has pulled in researchers' consideration. Additionally, SIS disappointments survey showed that the majority of those disappointments come from little consideration regarding authoritative characteristics of SIS (Brown, 1998). Subsequently, one of the ways to improve SIS achievement is to distinguish what hierarchical practices that could improve the likelihood of SIS achievement. Also, in view of research led on SIS achievement, it uncovered that there are visit calls for examining the interrelationships between authoritative angles what's more, SIS achievement (Bruque et al.,2008), (Bunker et al., 2007). In any case, investigate concentrated on the connection between firm-wide hierarchical angles and SIS achievement is somewhat constrained (Bunker et al., 2007). Henceforth, there is space for both hypothesis and practice to think about SIS accomplishment by completing an exhaustive exact investigation. The present investigation attempts to satisfy this need. In this way, the principle goal of this investigation is to audit and broaden the writing and propose 
experimental testing of the hypothetical system for SIS achievement. These advancement, disappointments, and past investigates lead the scientists to two significant ends.

Initially, the best SIS is coordinated such that better fits the affiliation properties (for instance culture, structure, style and limits). Second, in perspective on the centrality of various levelled perspectives, look at on SIS progressive creates can update the level of SIS learning. Looking into past systems/models on SIS achievement demonstrated that a few investigations have used a wide viewpoint, for example, SIS solution, basic achievement factors (Bhattacherjee \& Hikmet, 2007; Bunke et al., 2013; Burton-Jones, \& Gallivan, 2007) while others have utilized a restricted point of view of some hierarchical develops, for example, between gathering collaborations, authoritative responsibility (Bussen \& Myers, 1997; Caseley, 2004; Cerpa \& Verner, 2009). It very well may be inferred that there is no accord on a typical arrangement of authoritative develops for SIS achievement.

In addition, the proof from past examinations showed that exploration concentrated on the connection between firm-wide hierarchical angles and SIS achievement is constrained. The most shortcoming of these examinations was that they didn't see association as a heap of exercises, assets, resources, and procedures. In rundown, there isn't any extensive investigation of authoritative side of the SIS achievement.

Scientists trust that asset based perspective on the firm (RBV) can more readily fill this hole by thinking about the firm as a lot of assets and abilities. In a decades ago, the RBV hypothesis has increased expanding strength in the vital administration field and perspectives association as a heap of assets (Clegg, 1989). One of the primary ideas presented by RBV point of view in IS field IS ability (Delone \& McLean, 2003). IS ability is a perplexing gathering of IT-related assets, information and aptitudes rehearsed through hierarchical procedures and enable the firm to use IS/IT resources for wanted targets (DeLone \& McLean, 1992).

In this manner the key mastermind should most likely output the outer condition just as acquiring inside operational data. For example,(Devaraj \& Kohli, 2003). featured the criticalness of utilizing center supervisors inside the key detailing process. It was declared that methodologies figured with learning from center administration and other significant people inside an association, instead of simply the key scholar are probably going to be better as thought is given than both data viewing what activities are required just as whether the moves to be made are operationally conceivable as far as assets such as staff and materials. This was exemplified by (Clegg, 1989) who found that limit spanners which speak to people who perform jobs including the board, providers and clients are a significant wellspring of data. This is because of these people approaching important outer data that may help basic leadership.

So as to help a vital mastermind's "frameworks considering" (Devaraj \& Kohli, 2003). presented the idea of a methodology map that "gives a visual portrayal of an organization's basic destinations". The guide enables the vital mastermind to adjust any choices made with those of the organization's goals just as knowing about worker capabilities and innovation that will help/prevent the execution of the choice. With a perspective on a system map (recognizing the aggregate parts in the association), senior administration can see how actualizing a vital choice on one piece of the association may affect another. In this manner, as per this methodology, successful vital reasoning requires a comprehension of the interrelationships and between conditions of each piece of the association (Bussen \& Myers, 1997) and ought to be a competency found in great key leaders. Anyway, inquire about with respect to the skills required for vital reasoning and basic leadership has been meagre, in spite of the fact that the significance of recognizing such capabilities is recognized in the 
writing. As (Dwivedi et al., 2013) contended a comprehension of vital reasoning would profit by an examination concerning the attributes of an individual key scholar just as the elements and procedures that happen inside the hierarchical setting.

\section{Strategic Decisions Effectiveness}

Understanding key reasoning and basic leadership abilities has turned out to be significant as research has appeared great key capabilities are related with great hierarchical execution (Dwivedi et al., 2011). . In any case, there is no understanding, inside the writing, concerning what these abilities are. As indicated by (Clegg, 1989), strategists can be seen as specific or remarkable individuals, who set the bearings, settle on essential choices and support their adherents. Little consideration has been coordinated towards examining abilities that make them specific or extraordinary individuals. The significance of distinguishing such abilities was sketched out by (Bruque et al.,2008) who contends that "on the off chance that we need to clarify why associations do what they do, or, thusly, why they play out the manner in which they do, we should contemplate top administrators", who speak to vital masterminds and leaders, and the skills they have.

A competency is an aptitude that an individual and therefore the association has that empowers it to perform exercises (Clegg, 1989). Competency based key administration is the conviction that a few attributes and practices are shown all the more reliably by strategists which can be recognized, instructed and surveyed (Delone \& McLean, 2003). Hence, the idea of center skills (Burton-Jones, \& Gallivan, 2007) might be a valuable structure evaluating how vital masterminds make decisions that sway on the fate of the association. (Dwivedi et al., 2013). trusted that the capacity of those in any area to think deliberately is bound by the edges of reference with which they are most natural: the presumptions, convictions and collected information of a calling or foundation. In its broadest sense, "competency" alludes to the total of encounters and information, aptitudes, characteristics, parts of mental self view or social job, qualities and demeanors a strategist has obtained amid his or her lifetime (Bruque et al., 2008). It depends on past involvement as far as what has been effective and what has not. This was first advanced by (Cerpa \& Verner, 2009) in his original work on the intelligent expert. It is contended that experts apply formally learned and authority information to circumstances and create collections or answers for troublesome issues. The fundamental ability would be reflection where with each experience a vital chief would build up their insight into what will and what won't work. Research has been directed to distinguish the center abilities required to have the capacity to think deliberately and settle on key choices. (Delone \& McLean, 2003) recognized six groups of capabilities, which comprise of specialized abilities; business skills; learning the executives skills; administration capabilities; social skills and intrapersonal capabilities. Be that as it may, inside this arrangement of abilities there is an absence of reference to basic leadership, which is a fundamental part of the strategist's job and one that guides the association into what's to come. It is, in this manner, simpler to fathom the center capabilities into two worldwide skills; considering and basic leadership.

One component that has turned out to be clear in the administration writing is that choices are impacted by a person's convictions and qualities. From a mental point of view, (BurtonJones, \& Gallivan, 2007) characterized values as "alluring states, items, objectives or practices rising above explicit circumstances and connected as regularizing guidelines to pass judgment and to pick among elective methods of conduct". This definition features two significant capacities. In the first place, they are suffering and rise above circumstances; qualities can give rationality and a feeling of direction to a person's conduct. Second, since they are regulating principles esteems can frame the reason for creating practices that adjust to the necessities of gatherings or bigger social units (Clegg, 1989). 
Qualities fill in as solid casual administrative aides when deciding, and impact subjective procedures, for example, administrative insight. For instance, values determine methods of conduct that are socially adequate and fill in as a regularizing administrative guide for individual specialists (Caseley, 2004) and they have a long convention of shaping, coordinating and managing human conduct and basic leadership all through associations (Cerpa \& Verner, 2009). (Bunke et al., 2013) suggested that vital decisions/basic leadership are an impression of top administrators' subjective base (formed to a great extent through foundation experience and qualities). (Caseley, 2004) contend that choices are regularly sifted through frames of mind, convictions and qualities; poor basic leadership happens when the separating of the data clashes with individual observations and qualities and results in poor evaluation. These qualities are placed to saliently affect key decision through a procedure known as conduct directing (Bignell \& Fortune, 1984) whereby key leaders' qualities decide decision and their choice of proper vital activity. For instance, (Bunker et al., 2007) found from an investigation of 70 supervisors in 13 spas that their subjective styles and their method for handling data affected procedures they liked. Furthermore, values straightforwardly influenced decision through a procedure of "perceptual screening" which is a forming of the vital leader's restricted perspective on the association and its condition. As has been found inside the writing, when looked with a difficulty, a key leader regularly, yet not generally, depends without anyone else point of view of technique and how it identifies with the association and nature (DeLone \& McLean, 1992). Hence, technique is connected to a strategist's perspective on how the association ought to work and capacity (Caseley, 2004) and can influence basic leadership. Given that administrative perception impacts basic leadership and aggressive methodologies (Bunke et al., 2013), the subjective parts of strategists is critical to our comprehension of how focused associations are created. The psychological model sees chiefs as attempting to create an all out perspective on the earth, which depends on inadequate information (Devaraj \& Kohli, 2003). . Strategists attempt to disentangle the inadequate data they have dependent on their past experience and claim intellectual styles. In this way any choices made would be made dependent on the strategist's qualities, convictions and experience, which at last could confine the decisions that they make. Basically then qualities fill in as diagrams or establishments for deciding, taking care of issues and settling clashes. It is the point at which these qualities become a block to settling on the choice that issues emerge. Each venture is driven by its pioneers' individual and aggregate qualities, regardless of whether these qualities are deliberately comprehended, or unknowingly compelling, spoken or implicit, composed or unrecorded.

\section{Conclusion}

In short, strategists endeavour to improve the fragmented data they have dependent on their past experience and claim intellectual styles. In this way any choices made would be made dependent on the strategist's qualities, convictions and experience, which at last could confine the decisions that they make. Basically then qualities fill in as outlines or establishments for deciding, tackling issues and settling clashes. It is the point at which these qualities become an obstruction to settling on the choice that issues emerge. Each venture is driven by its pioneers' individual and aggregate qualities, regardless of whether these qualities are intentionally comprehended, or unknowingly persuasive, spoken or implicit, composed or unrecorded. Notwithstanding, a strategist's qualities limit their field of vision, influence their particular discernment, impact their elucidation of data and mirror the decisions that they make. This is because of limited judiciousness whereby people settle on choices dependent on a standard guideline approach, whereby sound estimations are settled on and choices give off an impression of being in their very own best interests. It is a programmed pre-cognizant procedure that is hard to change. It is fundamental, 
consequently, for strategists to see how their duties to the errand and obligations tie them to extraordinary qualities and purposes just as how their feeling of importance and incorporation is put into the strategist's job. Notwithstanding, it isn't simply close to home estimations that can affect the vital course of the association.

\section{References}

Akroyd, C., \& Maguire, W. (2011). The roles of management control in a product development setting. Qualitative Research in Accounting \& Management, 8(3), 212-237.

Al Jabouri, A. A. N., \& Kadhum, S. A. (2021). Flying instruments and their impact on the national economy and the extent of their control (CTS guidelines model).

Al-Ani, S., \& FLAYYIH, H. (2018). Principles of Financial Accounting. Al-Mihajat Printing and Reproduction Office. Baghdad, Iraq.

Alkhafaji, A. A., Talab, H. R., Flayyih, H. H., \& Hussein, N. A. (2018). The Impact Of Management Control Systems (Mcs) On Organizations Performance A Literature Review. Journal of Economics and Administrative Sciences, 24(105), 1-20.

Al-taie, B. F. \& Flayyih, H. H. (2020). Intermediate Accounting. Al-Mihajat Printing and Reproduction Office. Baghdad, Iraq.

Auzair, S. M., \& Langfield-Smith, K. (2005). The effect of service process type, business strategy and life cycle stage on bureaucratic MCS in service organizations. Management Accounting Research, 16(4), 399-421.

Bhattacherjee, A., \& Hikmet, N. (2007). Physicians' resistancetoward healthcare information technology: a theoretical modeland empirical test. European Journal of Information Systems,16(6), 725-737.

Bignell, V., \& Fortune, J. (1984). Understanding Systems Failure:Manchester University Press.

Brown, A. D. (1998). Narrative, politics and legitimacy in an it implementation. Journal of Management Studies, 35(1), 35-58.

Bruque, S., Moyano, J., \& Eisenberg, J. (2008). "Individual adaptation toit-induced change: the role of social networks,". Journal ofManagement Information Systems, 25(3), 177-206.

Bunker, D. J., Kautz, K., \& Nguyen, A. (2007). The role of valuecompatibility in it adoption. Journal of Information Technology,22, 69-78.

Bunker,D.,Levine,L.,\&Woody,C.(2013).RepertoiresofCollaborationfor Disaster Management: Negotiating Emergent and DynamicSystems Success. In proceedings of Grand Successes and Failuresin IT IFIP WG8.6 Working Conference Bangalore, India June 27 -29, 2013.

Burton-Jones, A.,\& Gallivan, M. J.(2007).Toward a deeperunderstanding of system usage in organizations: a multilevel perspective. MISQuarterly, 31(4), 657-679.

Bussen, W., \& Myers, M. D. (1997). Executive information systemfailure: a New Zealand case study. Journal of InformationTechnology, 12(2), 145-153.

Caseley, J. (2004). Public sector reform and corruption: card facade inAndhra Pradesh. Economic and Political Weekly, 39(11), 1151-1156.

Cerpa, N., \& Verner, J. M. (2009). Why did your project fail?Communications of the ACM, 52(12), 130134.

Chenhall, R. H. (2003). Management control systems design within its organizational context: findings from contingency-based research and directions for the future. Accounting, organizations and society, 28(2), 127-168.

Clegg, S. (1989). Frameworks of power. London: Sage Publications.

DeLone, W. H., \& McLean, E. R. (1992). Information systems success: the quest for the dependent variable. Information Systems Research,3(1), 60-95.

Delone, W. H., \& McLean, E. R. (2003). The delone and Mclean modelof information systems success: a ten-year update. Journal ofManagement Information Systems, 19(4), 9-30.

Devaraj, S., \& Kohli, R. (2003). Performance impacts of informationtechnology: is actual usage the missing link? Management Science,49(3), 273-289.

Dwivedi, Y. K., Kapoor, K. K., Williams, M. D., \& Williams, J. (2013a).RFID systems in libraries: an empirical examination of factorsaffecting system use and user satisfaction. International Journal ofInformation Management, 33(2), 367-377. 
Dwivedi, Y. K., Weerakkody, V., \& Janssen, M. (2011). Moving towardsmaturity: challenges to successful e-government implementationand diffusion. The DATA BASE for Advances in InformationSystems, 42(4), 11-22.

Flayyih, H. H., Salih, J. I., Rahma, N. G. A., \& Mohammed, Y. N. (2020). Earnings Management between the fact of manipulation and credibility of management procedures: a literature review. Social Science and Humanities Journal, 1908.

Hall, J. A. (2008). Accounting information systems. Cengage Learning.

Henri, J. F. (2006). Management control systems and strategy: A resource-based perspective. Accounting, organizations and society, 31(6), 529-558.

Henri, J. F., \& Journeault, M. (2010). Eco-control: The influence of management control systems on environmental and economic performance.Accounting, Organizations and Society, 35(1), 63-80.

Landfield, Kent B, \& Zechmann, Albert J. (1997). Electronic mail management system for operation on a host computer system: Google Patents

Romney, M., and Steinbart, P. (2009). Accounting Information Systems (ed.). Upper Saddle River, NJ: PrenticeHall.

Thijeel, A. M., Flayyih, H. H., and Talab, H. R. (2018). The relationship between audit quality and accounting conservatism in the Iraqi banks. Opción, 34, 1564-1592.

Watts, Ted, \& McNair-Connolly, Carol J. (2012). New performance measurement and management control systems. Journal of Applied Accounting Research, 13(3), 226-241. 